\title{
Aminoácidos para frangos de corte
}

\section{Adhemar Rodrigues de Oliveira Neto1, Will P. de Oliveira²}

\author{
1 Evonik Degussa do Brasil Ltda. \\ ${ }^{2}$ Universidade Federal de Viçosa - Doutorando do Departamento de Zootecnia
}

RESUMO - A utilização de aminoácidos digestíveis e da proteína ideal auxiliou a reduzir as excreções de nitrogênio para o ambiente e o custo da ração formulada, sem afetar negativamente o desempenho dos frangos de corte. Entretanto, apesar de ser reconhecido como a melhor ferramenta atual para se formular rações, alguns fatores ainda devem ser elucidados para a melhor utilização do conceito de proteína ideal e para se alcançar o melhor desempenho das aves. Estes fatores são: o conhecimento das exigências dos aminoácidos não essenciais; a utilização do bom senso nas metodologias empregadas para se definir as exigências de aminoácidos; o conhecimento das exigências dos aminoácidos e a definição da proteína ideal para aves criadas em diferentes condições ambientais e sanitárias.

Palavras-chave: condições ambientais, exigência de aminoácidos essenciais, proteína ideal, sanidade

\section{Amino acids for broilers}

\begin{abstract}
Utilization of digestible amino acid and ideal protein concepts helped to reduce environmental nitrogen excretion and the feed formulation cost without to cause bad performance in broilers. Nevertheless, besides to be recognized that is the best tool at the moment, some factors still should be elucidate to obtain the best utilization of the ideal protein and to reach the best broiler performance. These factors are: knowing about non essential amino acids requirement; utilization good sense to use methodologies to reach amino acid requirement; knowing about amino acid requirement and ideal protein definition for broiler raised in environment and health different.
\end{abstract}

Key Words: essential amino acids requirement, environment conditions, health conditions, ideal protein

\section{Introdução}

Até pouco tempo atrás as rações para frangos de corte eram formuladas somente para atender o valor de proteína bruta. Posteriormente, os níveis de aminoácidos totais foram utilizados para atender as necessidades protéicas dos frangos de corte.

Contudo, embora a proteína e os aminoácidos totais tenham sido utilizados no passado para formular rações para aves, atualmente se emprega uma metodologia de formulação mais adequada, os aminoácidos digestíveis e as relações ideais entre a lisina e os demais aminoácidos.

Isto porque se sabe que o excesso de proteína ou o imbalanço entre os aminoácidos podem comprometer o desempenho dos frangos de corte, por promover uma carga excessiva de aminoácidos na circulação sanguínea que, para serem metabolizados, exigem um gasto extra de energia, a qual é desviada da produção para os processos de excreção do nitrogênio na forma de ácido úrico (Aletor et al., 2000). Este nitrogênio em excesso, excretado pelas aves, também pode provocar danos ao meio ambiente (Parsons $\&$ Baker, 1994). Fato que se agrava devido à grande quantidade de dejetos gerados pela atividade de produção animal e que tem se tornadouma questão muito preocupante nos tempos atuais.

O emprego de aminoácidos digestíveis e da proteína ideal permite que se reduza a excreção de nitrogênio além de permitir que rações de menor custo sejam produzidas, mantendo um adequado desempenho dos frangos de corte (Rostagno et al., 1997; Grana, 2008).

Entretanto é importante salientar que, embora seja a melhor ferramenta no momento, a utilização da proteína ideal para formular rações possui deve ser realizada com bom senso para que não sejam cometidos enganos, os quais podem levar a desempenhos não satisfatórios das aves. Com relação ao último comentário vale a pena ressaltar sobre a metodologia atual utilizada para estimar a exigência de frangos de corte. Nestes experimentos não se têm considerado a limitação pelos aminoácidos não essenciais . 
Ainda, muitas relações de aminoácidos devem ser confirmadas para se ter certeza da correta relação entre lisina e os demais aminoácidos. Ainda se encontram discrepâncias na literatura em relação as sugestões de diversos autores.

Por fim, a correta exigência de aminoácido para frangos de corte mantidos sob desafio sanitário não está devidamente estabelecida, havendo indícios na literatura de que estas relações podem ser diferentes dependendo da condição (ambiental e sanitária) em que os frangos de corte são submetidos.

\section{Proteína ideal}

Este conceito tem por objetivo evitar as possíveis perdas produtivas e reduzir o impacto da produção animal sobre o meio ambiente por meio da redução da carga de nutrientes presentes nas excretas (Mendonza et al., 2001; Faria Filho et al., 2006; Silva et al., 2006). No que se refere ao nitrogênio excretado pelas aves, a redução de seu teor nas excretas pode ser obtido reduzindo-se a participação de fontes naturais de proteína nas rações. Contudo é necessário garantir que as necessidades nutricionais dos frangos de corte sejam ainda atendidas de forma adequada.

Com a fabricação em escala industrial de aminoácidos sintéticos e sua disponibilidade no mercado, associado ao conhecimento de que a exigência nutricional das aves é principalmente por aminoácidos e não simplesmente pela proteína bruta da ração (Nascimento, 2004), tem sido possível formular rações com base no conceito de "proteína ideal". Este conceito torna possível reduzir o teor protéico das rações e, concomitantemente, manter os aminoácidos essenciais dentro dos níveis adequados às exigências das aves (Rostagno et al., 1999). A proteína ideal é, portanto, definido como um balanço exato de aminoácidos capaz de prover sem excesso ou déficit as necessidades de todos os aminoácidos essenciais, expressando-os como porcentagem da lisina. Assim, uma vez estabelecida a exigência de lisina, as exigências para os demais aminoácidos podem então ser facilmente calculada (Han \& Baker, 1994; Kidd et al., 1997; Martinez et al., 2002).

Apesar do uso do conceito da proteína ideal ter se consolidado com resultados positivos em setores de produção como o suinícola, os efeitos dessa prática sobre o desempenho de frangos de corte é uma questão que ainda não se encontra bem elucidada. Estudos já realizados sobre o assunto têm demonstrado que a redução da proteína bruta das rações suplementadas com aminoácidos essenciais não altera o desempenho e nem as características de carcaça de frangos. Entretanto, algumas vezes é possível encontrar trabalhos mostrando que a redução da proteína bruta pode piorar o desempenho e o rendimento de cortes nobres dos frangos (Sabino et al., 2004; Assis et al., 2008; Namround et al., 2008). A grande questão é entender porque em alguns trabalhos o emprego da proteína ideal se observa melhora enquanto em outros se observa piora no desempenho das aves.

Diferente do que alguns ainda acreditam, a redução da proteína bruta não provoca efeito nocivo sobre o desempenho e sobre o apetite dos frangos. Quando o desempenho dos frangos de corte é afetado formulando-se ração com o conceito de proteína ideal se deve a alguma falha na compreensão do emprego desta metodologia. Quando isto ocorre, algum fator, como: a deficiência de aminoácidos não-essenciais; a redução do nível de potássio ou alteração no balanço iônico, e ainda o imbalanço entre algum aminoácido podem explicar a piora encontrada.

\section{Aminoácidos não-essenciais}

Assumindo que aminoácidos não-essenciais podem estar sendo um fator limitante em dietas com baixo teor de proteína, pesquisas têm sido desenvolvidas para estudar os efeitos da redução a redução da proteína bruta da ração associada à suplementação simultânea tanto de aminoácidos essenciais quanto dos não-essenciais (Waldroup et al., 2005; Kerr \& Kidd, 1999).

Metodologia empregada para definir a exigência de aminoácido

Trabalho realizado por Balbino (2008) mostrou que a metodologia empregada para estimar a exigência de lisina para frango de corte pode influenciar o valor encontrado como sendo o ideal para o melhor ganho de peso e conversão alimentar destes.

Exigência de aminoácido em aves sob stress imunológico

O perfil de nutrientes utilizado em rações de frangos está baseado em pesquisas que avaliaram as funções produtivas economicamente importantes como: ganho de peso, consumo de ração, conversão alimentar e rendimento de cortes; mas não à imunidade ou à resistência a doenças (Kidd, 2004). Em situação de campo, muitas vezes os frangos são submetidos a agentes estressores infecciosos e ou não infecciosos que ativam o sistema imune desses animais (Norup et al 2008).

Quando o sistema imune é ativado, ocorrem alterações fisiológicas e metabólicas no organismo. Nesta condição, a prioridade do organismo animal passa a ser a proliferação de células de defesa, a expressão de receptores para reconhecer moléculas estranhas, a produção de citocinas moduladoras de resposta imune, a produção de anticorpos, 
além de outras moléculas efetoras. A produção de moléculas efetoras assim como intermediário reativo de oxigênio e nitrogênio pode modificar as necessidades nutricionais das aves (Tahakashi, 2006). Neste contesto, nutrientes com participação mais expressiva para deposição de carne e menos expressiva para funções de defesa, como a lisina, passam a ter importância reduzida para o organismo animal, enquanto outros, que participam mais expressivamente do sistema imune, como metionina, treonina, triptofano e arginina, passam a ser mais requerido sob tal circunstância.

Diversos pesquisadores relataram que os aminoácidos sulfurados como a metionina e a cisteína são importantes componentes de moléculas de defesa como as imunoglobolinas, agentes moduladores e sinalizadores de células do sistema imune, assim como constituintes de antioxidantes celulares como a glutationa (Tsiagbe et al., 1987; Takahashi et al., 1997 e 2006; Kidd, 2004; Hunter et al., 1994; Rubin et al., 2007).

Outra molécula importante e produzida em abundância quando o sistema imune está ativado é o óxido nítrico, um potente agente oxidante com função bactericida e sinalizadora para macrófagos. O óxido nítrico é sintetizado a partir da arginina (Sung et al., 1991). E as exigências desse aminoácido para se obter ótimo crescimento em frangos e outros animais, podem não ser adequada para ótima atividade citotóxica de macrófagos (Kidd, 2004).

Até mesmo a ativação imunológica intestinal pode contribuir para mudanças nos requerimentos aminoacídicos. $\mathrm{O}$ aumento da atividade imunológica intestinal contribui para o aumento da proliferação de células de defesa, produção de anticorpos e aumento na secreção de mucinas, proteínas constituintes do muco entérico, abundante em aminoácidos como a treonina. $\mathrm{O}$ aumento da utilização deste aminoácido pelo intestino pode desviá-lo das rotas de deposição de carne prejudicando o desempenho das aves. Embora não haja evidências de sua carência sobre o desenvolvimento dos orgãos imunitários ou as respostas celulares e humorais em frangos de corte, as deficiências de treonina parecem diminuir o crescimento e o desenvolvimento muscular desses animais (KIDD et al., 1997 e 2001). Dessa forma, tornam-se necessários estudos a fim de se estabelecer exigências nutricionais também para animais em situações de estresse imunológico.

\section{Considerações finais}

Apesar de ainda possuir limitações, o uso do conceito de proteína ideal na formulação de rações para frangos de corte é a ferramenta mais útil para reduzir a carga excessiva de proteínas fornecida aos animais, permitindo maiores ajustes dos níveis de aminoácidos ás reais exigências das aves, além de contribuir para a redução do impacto ambiental causado pela produção animal.

A metodologia empregada para estimar a exigência de lisina para frangos de corte devem ser cuidadosamente avaliada;

Estudos devem ser realizados para se conhecer as exigências de aminoácidos não essenciais, pois estes se tornam limitantes quando reduzimos a proteína bruta das rações de frango de corte.

Por fim, estudos para se definir a exigência de aminoácidos para aves criadas sob estresse imunológico deve ser conduzidos, pois existem evidências que podem ser alterados.

\section{Literatura Citada}

ALETOR, V.A.; HAMID, I.I.; NIESS, E. et al. Low-protein amino acid-supplemented diets in broiler chickens: Effect on performance, carcass characteristics, whole body composition and efficiencies nutrient utilization. Journal Science Food Agriculture, v.80, p.547-554, 2000.

ASSIS, A.P.; BALBINO, E.M.; CAMPOS, P.H.R.F. et al. Níveis de lisina em rações para frangos de corte machos mantidos em termoneutralidade dos 22 aos 42 dias de idade. In: Zootec 2008, 2008, João Pessoa. Anais... João Pessoa, 2008. (CD-ROM).

BALBINO, E.M. Níveis de lisina digestível em rações suplementadas ou não com aminoácidos industriais para frangos de corte mantidos em diferentes ambientes térmicos. 2008. 82f. Dissertação (Doutorado em Zootecnia) Universidade Federal de Viçosa, Viçosa, MG, 2008.

FARIA FILHO, D.E. Efeito de dietas com baixo teor protéico, formuladas usando o conceito de proteína ideal, para frangos de corte criados em temperaturas fria, termoneutra e quente. 2003. 93f. Dissertação (Mestrado em Zootecnia) - Faculdade de Ciências Agrárias e Veterinárias, Universidade Estadual Paulista, Jaboticabal, 2003.

GRANA, A.L. Estratégias nutricionais para frangos de corte. 2008. 102p. Dissertação (Doutorado em Zootecnia) Universidade Federal de Viçosa, Viçosa, 2008.

HAN, Y.; BAKER, D.H. Digestible lysine requirement of male and female broiler chicks during the period three to six weeks post hatching. Poultry Science, v.73, p.1739-1745, 1994.

HUNTER, E.A.L.; GRIMBLE, R.F. Cysteine and methionine supplementation modulate the effect of tumor necrosis factor a on protein synthesis, glutathione and zinc concentration of liver and lung in rats fed a low protein diet. Journal of Nutrition, v.124, p.2319-2328, 1994.

KERR, B. J.; KIDD, M.T. Amino acid supplementation of lowprotein broiler diets: 1. Glutamic acid and indispensable amino acid supplementation. Journal of Applied Poultry Research, v.8, p.298-309, 1999.

KIDD, M.T.; KERR, B.J.; ANTHONY, N.B. Dietary interactions between lysine and threonine in broilers. Poultry Science, v.76, p.608-614, 1997.

KIDD, M.T. Nutritional modulation of immune function in broilers. Poultry Science, v.83 p.650-657, 2004.

MARTINEZ, K.L.A.; PEZZATO, A.C.; GONÇALVES, J.C. et al. Níveis de lisina em rações formuladas a partir de aminoácidos totais e digestíveis para frangos de corte submetidos a diferentes 
temperaturas. In: REUNIÃO ANUAL DA SOCIEDADE BRASILEIRA DE ZOOTECNIA, 39, 2002, Recife. Anais... Recife: Sociedade Brasileira de Zootecnia. 2002. (CD-ROM).

MENDONZA, M.O.B.; COSTA, P.T.C.; KATZER, L.H. et al. Desempenho de frangos de corte, sexados, submetidos a dietas formuladas pelo conceito de proteína bruta versus proteína ideal.

Ciência Rural, v.31, p.111-115, 2001.

NAMROUND, N.F.; SHIVAZAD, M.; ZAGHARI, M. Effects of fortifying low crude protein diet with crystalline amino acids on performance, blood ammonia level, and excreta characteristics of broiler chicks. Poultry Science, v.87, p.2250-2258, 2008.

NASCIMENTO, A. Exigências de aminoácidos essenciais para frangos de corte. In: CONFERÊNCIA APINCO, 2004, Santos. Anais... Santos: Fundação Apinco de Ciência e Tecnologias Avícolas, 2004. p.103-116.

NORUP, L.R.; JENSEN, K.H.; JORGENSEN, E. et al. Effect of mild heat stress and mild infection pressure on immune responses to an E. coll infection in chickens. Animal, v.2, n.2, p.265$274,2008$.

PARSONS, C.M.; BAKER, D.H. The concept and use of ideal proteins in the feeding of nonruminants. In: SIMPÓSIO INTERNACIONAL DE PRODUÇÃO DE NÃO-RUMINANTES, 1994, Maringá. Anais... Maringá: SBZ, 1994. p.119-128.

ROSTAGNO, H.S.; NASCIMENTO, A.H.; ALBINO, L.F.T. Aminoácidos totais e digestíveis para aves. In: CONFERÊNCIA APINCO, 1999, Campinas. Anais... Campinas: Fundação Apinco de Ciência e Tecnologias Avícolas, 1999. p.65-83.
SABINO, H.F.N.; SAKOMURA, N.K.; NEME, R. et al. Níveis protéicos na ração de frangos de corte na fase de crescimento. Pesquisa Agropecuária Brasileira, v.39, p.407-412, 2004.

SILVA, Y.L.; RODRIGUES, P.B.; FREITAS, R.T.F. et al. Redução de proteína e fósforo em rações com fitase para frangos de corte no período de 1 a 21 dias de idade. Desempenho e teores de minerais na cama. Revista Brasileira de Zootecnia, v.35, p.840-848, 2006.

SUNG, Y.; HOTCHKISS, J.H.; AUSTIC, R.E. et al. L-argininedependent introduction of a reactive nitrogen intermediate by macrophages of a uricotelic species. Journal Leukocyte Biology, v.50, p.49-56, 1991.

TAHAKASHI, K.; OHTA, N.; AKIBA, Y. Influences of dietary methionine and cysteine on metabolic responses to immunological stress by Escherichia coli lipoploysaccharide injection, and mitogenic response in broiler chickens. Journal of Nutrition, v.78, p.815-821, 1997.

TAHAKASHI, K. Nutritional control of inflammatory responses in broiler chiken. Journal of Integrated Field Science, v.3, p.1-7, 2006.

TSIAGBE, V.K.; COOK, M.E.; HARPER, A.E. et al. Efficacy of cysteine in replacing methionine in the immune responses of broiler chicks. Poultry Science, v.66, p.1138-1146, 1987.

WALDROUP, P.W.; JIANG, Q.; FRITTS, C.A. Effects of glycine and threonine supplementation on performance of broiler chicks fed diets low in crude protein. International Journal Poultry Science, v.4, p.250-257, 2005. 